\title{
Capsule Commentary on Satre et al., "Interventions to Reduce Unhealthy Alcohol Use among Primary Care Patients with HIV: the Health and Motivation Randomized Clinical Trial"
}

Lori D. Karan, $M D$

Internal Medicine and Preventive Medicine, Loma Linda University Medical School, Loma Linda, USA.

$\mathrm{J}$ Gen Intern Med 34(10):2189

DOI: $10.1007 / \mathrm{s} 11606-019-05171-8$

(1) Society of General Internal Medicine (This is a U.S. government work and not under copyright protection in the U.S.; foreign copyright protection may apply) 2019

A total of 614 adult HIV-positive patients in Kaiser Permanente, San Francisco, who reported prior year unhealthy alcohol use were randomized to receive either 3 sessions of (a) motivational interviewing (MI), (b) information regarding alcohol risks by emailed feedback (EF) through an EHR patient portal, or (c) usual care (UC), which included Screening, Brief Intervention, and Referral to Treatment. ${ }^{1}$ The interventions were carried out by behavioral health specialists embedded in the primary care clinics. At 12 months all three arms reported declines in unhealthy alcohol use and alcohol related problems, with no significant differences between the groups. There were also no differences in antiretroviral therapy (ART) adherence between the groups. At 6 months, there was less-reported illegal drug use/misuse of prescription drugs other than marijuana in the MI arm than in either EF or UC. There was less unhealthy drinking in persons who reported low motivation to reduce drinking at baseline in those that received MI.

A shortcoming of the study is that the results are based on self-report of the subjects. There may be a bias towards the improvement of unhealthy behavior, ART adherence, and illicit drug use when it is socially desirable to tell the research assistant that behavioral improvements were accomplished. Paying the subjects for completion of different phases of the experiment may additionally bias the results. Even spending time accumulating baseline and interval data can influence outcomes, when the interventions are succinct. These seem to be shortcomings of all brief intervention literature that are not easily overcome by study design.

Understanding the relative effectiveness of behavioral counseling interventions can help clinicians improve patient- centered care. ${ }^{2}$ The contents of the MI and EF approaches in this study are provided in enough detail, so that they can be replicated. The results are generalizable and demonstrate the merits of all three modalities.

Future studies could compare alternate interventions such as contingency contracting and case management. Additional studies might investigate how the dose and timing of the interventions impact behavioral change. ${ }^{3,4}$ Another consideration is that the optimal type and dose of intervention might vary with the severity of unhealthy alcohol use. ${ }^{3,5}$

Corresponding Author: Lori D. Karan, MD; Internal Medicine and Preventive Medicine Loma Linda University Medical School, Loma Linda, USA (e-mail: lori.karan@gmail.com).

\section{Compliance with Ethical Standards:}

Conflict of Interest: The author declares that she does not have a conflict of interest.

\section{REFERENCES}

1. Satre DD, Leibowitz AS, Leyden W, Catz SL, Hare CG, Jang H, Lam JO Bryant KJ, Weisner CM, Sterling SA, Horberg M, Volberding P, Silverberg MJ (2019) "Interventions to Reduce Unhealthy Alcohol Use among Primary Care Patients with HIV: the Health and Motivation Randomized Clinical Trial." J Gen Intern Med DOI: https://doi.org/10. 1007/s11606-019-05065-9.

2. Bradley KA, Kivlahan DR. (2014) Bringing Patient-Centered Care to Patients With Alcohol Use Disorders. JAMA 311(18):1861-1862.

3. McCambridge J, Cunningham JA. (2013) "The early history of ideas on brief interventions for alcohol." Addiction. 109:538-546.

4. McCambridge J, and Saitz R (2017) "Rethinking brief interventions for alcohol in general practice." BMJ. 356;j116.

5. Glass JE, Hamilton AM, Powell BJ, Perron BE, Brown RT, Ilgen MA. (2015) "Specialty substance use disorder services following brief alcohol intervention: a metanalysis of randomized controlled trials." Addiction110:1404-1415.

Publisher's Note Springer Nature remains neutral with regard to jurisdictional claims in published maps and institutional affiliations.

Published online August 6, 2019 